\title{
PROJETO SISTEMA RESPIRATÓRIO AO ALCANCE DE TODOS - AÇÕES EDUCATIVAS DO MAH
}

\author{
*Renato Paulo Chopard, **Maria Cristina dos Santos Faustino
}

\section{RESUMO}

Um conjunto de ações educativas foi empreendido pela equipe do Museu de Anatomia Humana Prof. Alfonso Bovero (MAH), buscando incentivar e aprimorar a discussão de assuntos relativos à saúde humana. Essas ações destinaram-se ao público estudantil, nos seus vários níveis e também ao público leigo. De maio a dezembro de 2007 , realizaram-se duas exposições temático-temporárias versando sobre o sistema respiratório e sobre os órgãos dos sentidos; visitas monitoradas, visitas destinadas a portadores de necessidades especiais; oficinas didáticas a docentes sobre estratégias de ensino da Anatomia Humana; dois ciclos de palestras abertas à comunidade, tanto quanto exposições itinerantes do acervo do museu.

Palavras-chave: Ação educativa. Cultura. Extensão Universitária. Saúde humana.

\section{ABSTRACT}

Some educative actions were taken by the Museum of Human Anatomy Prof. Alfonso Bovero with the intention of stimulating and improving general discussions about human health. These actions focused on students in all levels, and also on the general public. From May to December of 2007 , the museum worked with: the presentation of two temporary exhibitions about respiratory system and sense organs, as well as itinerant exhibitions of the museums collection; monitored visits aimed at individuals with special needs; educational workshops for teachers, dealing with Human Anatomy and Health; and also with two cycles of lectures opened to the community.

Key words: Museum actions. Culture. University extension. Human health.

* Coordenador do Museu de Anatomia Humana Prof. Alfonso Bovero, Professor Associado do Departamento de Anatomia do Instituto de Ciências Biomédicas (ICB), da Universidade de São Paulo (USP), coordenador do projeto. ** Especialista em Museologia, Museu de Anatomia Humana Prof. Alfonso Bovero, ICB-USP, gestora do projeto. Endereço: MAH - Museu de Anatomia Humana Prof. Alfonso Bovero - ICB-USP. Av. Prof. Lineu Prestes, 24I5-05508-900 - São Paulo-SP - e-mail: mah@icb.usp.br. 


\section{INTRODUÇÃO}

O Museu de Anatomia Humana Prof. Alfonso Bovero (MAH), ciente das suas responsabilidades educativas e sociais, pretendeu, por meio de ações educativas e de sua mediação: levar o conhecimento e a reflexão aos estudantes do ensino básico (público e privado) acerca dos conteúdos relativos à composição e ao funcionamento do sistema respiratório humano e dos órgãos dos sentidos; sensibilizá-los para a necessidade de formação, prevenção/precauções e cuidados relativos à saúde; propiciar aos docentes alternativas concernentes ao ensino não formal da Anatomia Humana (BARROS, I998; BRESLER, I993); levar à discussão - do público leigo - o que há de atual em termos de males que afetam o nosso organismo. Tudo isso foi feito de maneira a proporcionar um feedback entre a universidade e a sociedade; e a tornar mais próximo o diálogo entre essas instituições, tanto quanto a ação extensiva da universidade na discussão de temas de interesse geral (VAN MENGH, I987; ALEXANDER, I979).

\section{AS AÇÕES EMPREENDIDAS PELO MAH - AS EXPOSIÇÕES TEMÁTICO- TEMPORÁRIAS}

Por meio das exposições temático-temporárias intituladas Sistema Respiratório ao Alcance de Todos e Órgãos dos Sentidos, os nossos visitantes conheceram um pouco mais sobre a composição e o funcionamento dos órgãos do corpo humano. Além disso, foram apresentadas algumas das implicações advindas do acometimento desses órgãos, dos agentes prejudiciais à saúde respiratória, tanto quanto se revelaram medidas simples de prevenção a serem adotadas para a manutenção de órgãos e sistemas saudáveis. Vale considerar que foi oferecido um enfoque todo especial à discussão sobre os malefícios do uso do tabaco, tema muito em voga nos dias atuais.

Nos ambientes bastante descontraídos das instalações das exposições, os visitantes podiam adentrar, por exemplo, as vias aéreas humanas, compreendendo qual o caminho pelo qual passa o ar até chegar aos pulmões. Ou então, aguçavam seu raciocínio na montagem do quebra-cabeças sobre sistema respiratório e praticavam jogos lúdicos sobre a ação dos órgãos dos sentidos (GRANA, I994; FALK, I986;
EVERED, I987). Tudo de maneira muito espontânea e divertida.

Outras das atividades aplicadas propiciaram ao público experiências singulares, aproximando-os de circunstâncias da vida real: foram testes quanto à capacidade respiratória (com a colaboração da equipe da Profa. Sylvia Lucia de Freitas, da Escola de Educação Física e Esportes - USP); uso dos kits da Experimentoteca da Estação Giência; a apresentação e análise de broncoscopia (Hospital Universitário); visualização de lâminas contendo minúcias dos órgãos apresentados e a comparação de seus conteúdos às peças anatômicas (saudáveis e patológicas) que constaram do acervo exposto.

Complementarmente, utilizamos painéis educativos pelos quais ilustraram-se temas de Nutrição, exercícios físicos, males dos sistema respiratório e órgãos dos sentidos. A intenção foi a de provocar e envolver o visitante, da forma mais abrangente possível, de modo a alertá-lo quanto a sua postura em prol da boa saúde individual e coletiva.

Gabe aqui relatar a ação educativa desenvolvida com alunas do EJA (Ensino de Jovens e Adultos), portadoras de deficiência visual, que visitaram o MAH, sendo-lhes demonstrado acervo relativo ao sistema nervoso central (encéfalo), aplicando-lhes experimentos táteis e olfativos. A iniciativa pretendeu consolidar os conhecimentos teóricos adquiridos sob a educação formal.

\section{AS OFICINAS DIDÁTICAS}

Grande parte do público do MAH compõe-se de estudantes do ensino fundamental, médio e profissionalizante nas diversas áreas da saúde; então, em maio de 2007, uma oficina piloto foi oferecida a docentes das disciplinas de Biologia, Ciências e áreas afins. $\mathrm{Na}$ ocasião, bolsistas e técnicos do MAH expuseram sobre a missão e a história do museu, no tocante à difusão e facilitação na veiculação das ciências, notadamente da Anatomia Humana, e apresentaram exemplares de peças anatômicas reais, cujas especificidades de conservação foram detalhadas. Além disso, exercitaram estratégias de ensino da Anatomia Humana, sob aspectos não formais, que poderiam ser integrados ao dia a dia dos estudantes, na própria escola. 


\section{OS CICLOS DE PALESTRAS}

Ao longo do primeiro e segundo semestres de 2007, nos I e II Giclo de Palestras do MAH, contamos com a colaboração inestimável de docentes da Universidade, especialistas, doutores e mestres dos vários programas de pós-graduação da USP, que compartilharam as suas experiências, abordando, de forma sumamente qualificada, questões fundamentais como "Emergências Respiratórias", "Tabagismo", "Qualidade de vida", "Males que acometem o sistema respiratório", "Alergias", "Princípios físicos da audição e da visão", "Estímulos sensoriais à pele e à audição", "Deglutição", "Estímulo dos sabores"; "Alterações da audição"; "Ritmos biológicos" e "Males e especificidades da visão". Essas palestras destinaram-se à comunidade externa e da Universidade, e foram plenamente acompanhadas por alunos de graduação de diversas instituições de ensino das áreas da saúde, pelo público leigo e profissionais especializados. Observamos que, dada a linguagem acessível das discussões, a importância dos temas e a curiosidade latente do público, o diálogo academia-comunidade operou-se de maneira fluente e profunda (LUCAS, I983; THIER, I975).

\section{AS EXPOSIÇÕES ITINERANTES (PROGRAMA A UNIVERSIDADE E AS PROFISSÕES E SEMANA DA CIÊNCIA E TECNOLOGIA)}

Durante as duas exposições, que ocorreram respectivamente no período de 9 a II de agosto de 2007 , no edifício de Geografia/História (FFLCH) e de I a 7 de outubro de 2007, na Praça do Relógio (Cidade Universitária) e no Parque do Ibirapuera, foi possível despertar o interesse tanto de estudantes do ensino médio, para as alternativas às suas opções nos vestibulares e posteriores cursos de formação universitária, como do público em geral. Ambos se sensibilizaram com o contato com a diversidade e peculiaridades da complexa estrutura que compõe o corpo humano.

\section{CONSIDERAÇÕES FINAIS}

É nossa opinião que as práticas empreendidas pelo museu permitiram a conexão ideal entre a Universidade e seu público, bem como entre as várias instâncias universitárias e seus pares. São práticas que culminaram com o estabelecimento de parcerias entre instituições da USP e externas, numa multidisciplinaridade sem par. Para os nossos alunos, representaram uma amostra de como deve ser a sua postura e atuação: extremamente ética, voltada ao bem comum. Para os docentes, constituíram-se na árdua tarefa de tornar tanto mais acessível e palatável o contato, a interpretação, a compreensão e a transmissão dos temas pesquisados num nível científico-cultural de excelência, aquele específico da academia.

Neste aspecto, podemos dizer que o MAH realmente exerceu seu papel e representou uma função social muito coerente. Incentivando a troca de experiências, a interação e os debates, proporcionou um verdadeiro desafio a todos os envolvidos; depreendendo-se ser fundamental persistirem os incentivos contínuos a ações semelhantes.

Desse gênero de iniciativa, portanto, vislumbrou-se a fotografia da produção universitária, refletida na população que passou assim a adotar uma atitude mais crítica, mais consciente e responsável, uma verdadeira atitude cidadã.

Concluímos, enfim, que a cultura e extensão universitária, veiculadas por ações tais quais as realizadas pelo MAH, abrem democraticamente os portões da Universidade a todos os membros da sociedade, sem quaisquer distinções. Entende-se que, somente por esta forma de difusão das ciências, se opera uma comunicação certeira, sem ruídos, sem obstáculos intransponíveis, em que os frutos intelectuais, tecnológicos e culturais gerados são também colocados à prova de sua clientela mais fundamental - a da comunidade, do cidadão, dos seres humanos. É preciso incentivar o feedback contínuo entre os agentes; porque, assim, diagnósticos e avaliações melhor elaborados indicarão quais os novos caminhos a serem trilhados.

\section{AGRADECIMENTOS}

Agradecemos a colaboração e parceria dos professores: Sylvia Lucia de Freitas e monitores (EEFEUSP); Thaís Tinuci (EEFE-USP); João Paulo Becker Lotufo e Fábio Jacob (HU-USP); Paulo Saldiva, Rafael Stelmach, Maria do Patrocínio Tenório Nunes (FMUSP); Antônio Carlos Pereira Gomes (ICB-USP); 
Mikiya Muramatsu (IF-USP); Celisa Sera e equipe (FM-USP); Luiz S. Menna Barreto (EACH-USP); Dr. Ronaldo Frizzarini; Dr. José Américo Bonatti.

Aos auxílios financeiros obtidos e de materiais fornecidos: à Pró-Reitoria de Cultura e Extensão Universitária da USP, pela concessão de bolsas em nível de iniciação científica e de verba para divulgação das iniciativas; à Fundação Faculdade de Medicina pela concessão de verba para divulgação das iniciativas; à Brasil Health Service, pela concessão de peak flows meters.

Vale destacar que a parceria com a equipe Antitabagismo do Hospital Universitário resultou na aprovação da primeira fase de um projeto de políticas públicas da Fapesp, versando sobre campanha implementada no âmbito do município de São Paulo e de outros da grande São Paulo, com escolas públicas e privadas, além de outras instituições.

\section{REFERÊNCIAS BIBLIOGRÁFICAS}

ALEXANDER, E. P. Museums in Motion. An Introduction to the History of Museums. American Association for State and History. Nashivile, I979.

BARROS, H. L.; GRESTANA, S.; GASTRO, M.G.; PEREIRA, G. R. M. (org.). Centros e Museus de Giência - visões e experiências - subsídios para um programa nacional de popularização da ciência. São Paulo, Saraiva, I998. p. I97-203.

BOISVERT \& SLEZ. The Relationship between Exhibit Characteristics and Learning - Associated Behaviors in a Science Discovery Museum. Science Education, I995. p. 503-5I8.

BORUN, Minda. The Exhibit as Educator: Assessing the Impact. Journal of Museum Education, I992. v. I7, n. 3, p. I3-I4

BRESLER, G. A. Museums and Environmental Education. NAPEG Quartely, I99I.

CHAGAS, Isabel. Aprendizagem Não Formal/ Formal das Giências. Relação entre os Museus de Ciências e as Escolas. Revista de Educação, Dep. de Ed. da Faculdade de Giências da Universidade de Lisboa, v. 3, n. I, p. 5I-59, jun. I993.

CRANE, V.; NICHOLSON, T.; GHEN, M. Informal Science Learning, in What the Research Says About Television, Science Museums and Community Based Projects. Ephrata, Pennsylvania, Science Press, I994.
DUESING, S. Science Centers and Exploratories: A Look at Active Participation. In D. Evered \& M. O'Connor (eds.), Communicating Science to the Public. London, J. Wiley \& Sons (Ciba Conference Foundation), I987. p. I3I-I42.

FALK, J. H.; KORAN, J. J. Jr.; DIERKING, L. D. The Things of Science: Assessing the Learning Potential of Science Museums. Science Education, I986. p. 503508.

FORQUIN, J. C. Saberes escolares, imperativos didáticos e dinâmicas sociais. In: Teoria e Educação, I992. n. 5, p. 28-49.

GINSBURSH, V.; MAIRESSE, F. Defining a Museum: Suggestions for an Alternative Approach. Museum Management and Curatorship, I997. v. I6, n. I, p. I5-33.

LUCAS. A. M. Science Literacy and Informal Learning. Studies in Science Education, I983. n. IO, p. I-36.

THIER, H. D.; LINN, M. C. The Value of Interactive Learning Experiences in a Museum. Berkeley, Lawrence Hall of Science, University of California, (ERIC Document Reproduction Service n. ed. I82I56). I975.

VAN MENSH, P. Museums in Movement. A Stimulating Dynamic on The Interrelation Museology-Museums. Icofom Studies Series, I987. n. I7, p. I7-20. 